\title{
Alfabetização no Rio Grande do Norte - presença da professora Helena Botelho (1910-1920)
}

Literacy in Rio Grande do Norte - presence of teacher Helena Botelho (1910-1920)

Maria Arisnete Câmara de Morais

Karoline Louise Silva da Costa

Janaína Silva de Morais

Universidade Federal do Rio Grande do Norte

\section{Resumo}

Este trabalho tem o objetivo de compreender, em partes, o contexto político-educacional da época e do fazer pedagógico no que concerne aos ensinamentos da Leitura, da Escrita e das Lições de Coisas utilizadas 154 pela professora Helena Botelho de Farias no Grupo Escolar Joaquim Nabuco, em Taipú, Rio Grande do Norte (RN), entre as décadas de 1910 e 1920. O referencial teórico-metodológico fundamenta-se na História Cultural, que permite refletir acerca da apropriação da leitura e da escrita a partir dos objetos contextualizados nos quais emergem as maneiras diferenciadas do ensino-aprendizagem dessas habilidades. Dialogamos com as Leis e os Decretos do Governo do RN, Jornais, Revista, uma Cartilha e Livros de Escrituração Escolar. Observamos que - fazer pedagógico dessa professora centrava-se na intuição e nas Lições de Coisas consideradas a chave para desencadear a pretendida renovação do ensino nas primeiras décadas do século XX.

Palavras-chave: Leitura. Escrita. Lições de coisas.

\section{Abstract}

This paper analyses the practice of teaching Reading, Writing and Lessons Things of teacher Helena Botelho de Farias in Joaquim Nabuco School Group in Taipú, Rio Grande do Norte (RN). The theoretical and methodological framework that we use is based on Cultural History, which allows to reflect about the appropriation of reading and writing from the objects which emerge contextualized in different ways of teaching and learning of these abilities. We dialogued with the Laws and Decrees of the Government of RN, newspapers, magazines, one spelling book and records of bookkeeping school. We observed that this teacher pedagogical practice has focused on intuition and on the lessons of things considered thekey to trigger the desired renewal of the teaching in the first decades of the twentieth century.

Keywords: Reading. Writing. Lessons things. 
As escolas têm surgido por toda parte, os mestres se multiplicam, desinteressados e abnegados, como verdadeiros apóstolos. Todos sentem a necessidade de aprender a ler e escrever. (DANTAS, $1917)$.

\section{Palavras iniciais}

Este artigo faz parte do Projeto História da Leitura e da Escrita no Rio Grande do Norte: presença de professoras (1910-1940) / Conselho Nacional de Desenvolvimento Científico e Tecnológico (CNPq), desenvolvido no Grupo de Pesquisa História da Educação, Literatura e Gênero/Universidade Federal do Rio Grande do Norte (UFRN). O referido projeto objetiva contribuir para a historiografia da educação no Brasil e, em especial, no Rio Grande do Norte, configurando a leitura e a escrita, sob a ótica da presença de professoras, cuja prática docente ocorreu nos Grupos Escolares. (MORAIS, 2011 ).

Entre a presença de professoras, destacamos, neste trabalho, Helena Botelho de Farias, formada pela primeira turma da Escola Normal de Natal, em 1910. Evidenciamos a sua prática de ensino da Leitura, da Escrita e das Lições de Coisas no Grupo Escolar Joaquim Nabuco, em Taipú, Rio Grande do Norte, durante o período de 1919 a 1920. O objetivo é compreender, em partes, o contexto político-educacional da época e do fazer pedagógico no que concerne aos ensinamentos da Leitura, da Escrita e das Lições de Coisas. Indagamos: Como se deu a prática alfabetizadora da professora Helena Botelho?

trabalho fundamenta-se metodologicamente nas teorizações de Chartier (1990) que permite refletir as realidades históricas e os modos diferenciados de apropriação da leitura e da escrita configurados na construção do contexto, no qual emergem as maneiras do ensino-aprendizagem dessas habilidades, pensadas e dada a ler. Ainda fundamenta-se em Morais (2002), por permite pensar acerca da apropriação da leitura e da escrita a partir dos objetos contextualizados nos quais emergem as maneiras diferenciadas do ensino-aprendizagem dessas habilidades. E em Certeau (2012), ao possibilitar a reflexão sobre a lógica do cotidiano, as questões e os comportamentos do dia a dia que envolvem os espaços escolares e como professores e alunos legitimam saberes e valores que permeiam as práticas do coletivo escolar 
e inventam "artes de fazer", "astúcias sutis", "táticas de resistência" que vão alterando os objetos e os códigos, e estabelecendo uma (re)apropriação do espaço e do uso ao jeito de cada um.

Saber ler e escrever representava a inserção no mundo letrado, uma nova forma de apreender o mundo. São práticas que visavam "[...] reconhecer uma identidade social, exibir uma maneira própria de estar no mundo, significa simbolicamente em estatuto e uma posição", como também, "[...] as formas institucionais e objetivadas graças as quais uns 'representantes' (instâncias coletivas ou pessoas singulares) marcam de forma visível e perpetuada a existência do grupo, da classe e da comunidade." (CHARTIER, 1990, p. 23).

Pesquisamos no Instituto Histórico e Geográfico do Rio Grande do Norte (IHGRN), no Arquivo Público do Estado do RN e na Escola Estadual Joaquim Nabuco (Taipú/RN). Nesses acervos dialogamos com as Leis e os Decretos do Governo do Rio Grande do Norte; os jornais A República e Diário do Natal; a Revista de Ensino; Livros de Honra e de Matrícula; o Diário de Classe; o Regimento Interno dos Grupos Escolares; e a Cartilha de Ensino Rápido da Leitura.

Ressaltamos as dificuldades para analisar a vivência dos alunos, haja vista a ausência deste indício, que normalmente se perde com o tempo, impossibilitando o entrecruzamento com o registro do fazer docente. Entretanto, utilizamos o Diário de Classe de Helena Botelho e as publicações do Jornal A República no que se refere às visitas escolares e os passeios relacionados ao Grupo Escolar Joaquim Nabuco; além das orientações de Nestor dos Santos Lima sobre a Leitura, a Escrita e as Lições de Coisas para a escola primária do Rio Grande do Norte. São produções que indicam as demonstrações acerca dos padrões de conduta no início do século XX.

Realizamos entrevista com o senhor Odúlio Botelho de Medeiros, familiar da professora Helena Botelho, a respeito de seu modo de ser e conviver. Compreendemos que apesar do nosso esforço em configurar um determinado período histórico, sempre encontraremos lacunas na construção de um contexto.

\section{Alfabetização no Rio Grande do Norte}

As primeiras décadas do século XX foram marcadas pela tentativa de organização do ensino primário no Rio Grande do Norte. Na administração 
do governador Antônio de Souza (1907-1908) ocorreu a reforma na educação pública que "[...] autorizou o governo a reformar a instrução pública, dando especificamente ao ensino primário moldes mais amplos e garantidores de sua proficuidade." (LEI N 249, DE 22 DE NOVEMBRO DE 1907, p. 5). No período em questão a tônica centrava-se nas discussões sobre a criação dos Grupos Escolares, a expansão do ensino primário no Estado e a formação de professores.

Decreto n. 178, de 29 de abril de 1908, criou o Grupo Escolar Augusto Severo, o primeiro do Estado - localizado em Natal - e reabriu a Escola Normal de Natal com a finalidade de suprir o Estado com profissionais de educação qualificados.

A Reforma da Instrução Pública no Estado decretou a criação de "[...] pelo menos, um grupo escolar em cada município" e estabeleceu que seriam "[...] efetivamente providos nas cadeiras primárias os professores titulados pela Escola Normal." (LEI No 284, DE 30 DE NOVEMBRO DE 1909, p. 1).

Concluído o curso Normal, os professores estavam qualificados para a docência em qualquer instituição primária do Rio Grande do Norte. As informações demonstram que nesse período, ocorreu intenso deslocamento do professorado pelos recantos do Estado. Começava, então, a expansão do ensino primário. Tanto é que, em 1919, já funcionavam trinta e dois Grupos Escolares no Rio Grande do Norte.

Em viagem pelo interior do Estado, Manuel Dantas relatou: "Quem viaja presentemente pelo interior vê por toda a parte a mesma preocupação, o mesmo afã em favor do ensino [...] as escolas se multiplicam." (DANTAS, 1917, p. 1). Tanto é verdade que o escritor Ezequiel Wanderley, com o pseudônimo de Juquinha das Mercês, registrou esse momento educacional no poema Desanalfabetização, publicado no Jornal A República:

Uma verdade corrente

Vai correndo, imprensa a fora:

- Hoje aprende muita gente

Que não aprendera outrora.

Professores, de hora em hora

Vemos um em nossa frente...

E analfabetos de agora 
Só nos surgem por semente!

Deus queira que essa Instrução

Mais e mais se dissemine

Pelos recantos do Estado

E que chegue à perfeição

- De haver mais quem nos ensine

Do que quem seja ensinado!

(MERCÊS, 1922, p. 1)

Nesse contexto, como é retratado no poema, difundia-se o movimento nacional contra o analfabetismo no qual procurava disseminar a instrução pública por todos os estados da nação. Para Carvalho (2003, p. 227), nessa nova lógica "[...] o analfabetismo é alçado ao estatuto de marca da inaptidão do país para o progresso." Combatê-lo seria prioridade nas providências da reforma educacional.

No Estado do Rio Grande do Norte, a luta contra o analfabetismo se destacava com as discussões de educadores e dirigentes envolvidos com a instrução pública no país. A exemplo de Manuel Dantas, que declarou: "Não

158 sei se noutros Estados, observa-se o mesmo fenômeno, mas, no Rio Grande do Norte, a luta contra o analfabetismo vai se tornando tenaz e constante." (DANTAS, 1917, p. 1). Para divulgar a ideia de progresso, expressões como "Combater o analfabetismo é dever de honra de todo brasileiro" tomavam conta das páginas dos jornais. (COMBATER..., 1917; 1918; 1919).

Este movimento voltava-se para o ensino da Leitura e da Escrita na educação primária potiguar. A política educacional da época em estudo, apregoava que "[...] o fundamento do ensino primário consiste em leitura, escrita, cálculo e desenho, que serão cuidadosamente seriados, constituindo as demais matérias os elementos acessórios da instrução primária." (LEI N 405, DE 29 DE NOVEMBRO DE 1916, p. 45).

Nos documentos analisados, encontramos várias alusões à importância da Leitura e da Escrita nas escolas primárias. O texto de Oscar Wanderley enaltecia o esforço bem orientado dos professores, que "[...] estão se aparelhando de métodos e processos magníficos." (WANDERLEY, 1917, p. 5).

Para Nestor dos Santos Lima, diretor da Escola Normal de Natal, " [... ] a leitura é a base de todo ensino." Sem o propósito de investigar a história da 
leitura e da escrita nem o seus preceitos como arte, importa saber a sua aquisição no período estudado. (LIMA, 1911 , p. 1).

\section{Helena Botelho, uma breve história}

Helena Botelho de Farias, nasceu no Estado de Pernambuco em 13 de agosto de 1896, filha do casal José Paulino de Carvalho Botelho e Maria Marcolina Botelho. Quando criança Helena Botelho teve o primeiro contato com as letras através de sua genitora. "A família, por tradição, inclinou-se para as letras, artes, música e pelo magistério, como foi o caso de Josefa Botelho e de suas irmãs Helena e Alzira." (MEDEIROS, 2013).

Aos 16 anos de idade, ingressou na Escola Normal de Natal, onde fez parte da primeira turma de formandos, em 04 de dezembro de 1910. Nessa referida turma formaram-se,

Luiz Antonio dos Santos Lima, Severino Bezerra de Melo, Manuel Tavares Guerreiro, Anfilóquio Carlos Soares Câmara, Francisco Ivo Cavalcanti, José Rodrigues Filho, Luiz Garcia Soares de Araújo, Ecila Pegado Cortez, Judite de Castro Barbosa, Áurea Fernandes Barros, Olda Marinho, Stela Vésper Ferreira Gonçalves, Beatriz Cortez, Arcelina Fernandes, Guiomar de França, Anita de Oliveira, Francisca Soares da Câmara, Maria Natália da Fonseca, Maria Abigail Mendonça, Maria das Graças Pio, Clara Fagundes, Maria da Conceição Fagundes, Maria Julieta de Oliveira, Maria Belém Câmara, Maria do Carmo Navarro, Helena Botelho, Josefa Botelho. (MORAIS, 2006, p. 75).

Formavam-se vinte e sete alunos, cuja maioria pertencia ao sexo feminino: sete homens e vinte mulheres. Isso evidencia o fato de que o magistério era considerado uma extensão da maternidade e uma profissão predominantemente feminina. 


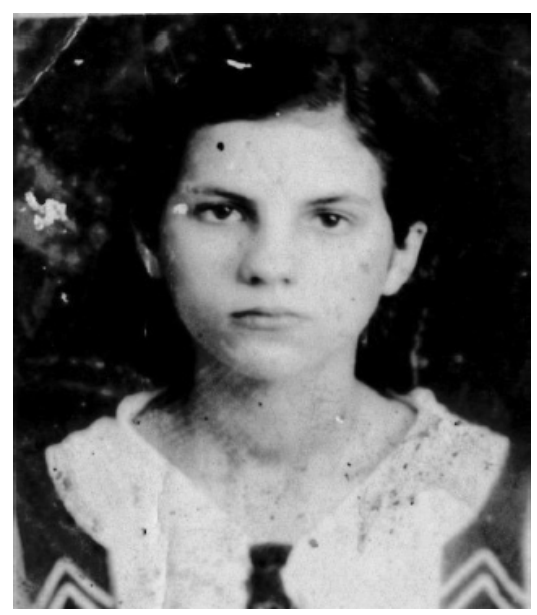

tmagem 1 | Helena Botelho | década de 1920 Fonte | Acervo pessoal de Haroldo Brandão

Aprovada em concurso público, Helena Botelho foi nomeada para exercer a docência no Grupo Escolar Senador Guerra (Decreto n 189, de 16 de fevereiro de 1909), instalado na cidade de Caicó/RN. Helena e a sua irmã Josefa Botelho, "[...] foram as primeiras professoras formadas a atuarem naquela cidade." (MORAIS; SILVA, 201 1, p. 71). Nesse estabelecimento de ensino ela lecionou durante o período de 1911 a 1918. Uma de suas alunas foi a educadora Chicuta Nolasco Fernandes que, posteriormente, dirigiu a Escola Normal de Natal, no período de 1952 a 1956. Dona Chicuta rememorava a sua professora primária enquanto estudante daquela instituição: "Adorava D. Helena, bonita como um cromo." (MORAIS, 2006, p. 39).

Lecionou em vários estabelecimentos de ensino: o Grupo Escolar Joaquim Nabuco na cidade de Taipú/RN, criado pelo Decreto n 86, 8 de janeiro de 1919 e o Grupo Escolar Pedro Velho, em Canguaretama, criado pelo Decreto $n^{\circ} 286,10$ de julho de 1913.

Finalmente, em 1923 foi transferida, a pedido, do Grupo Escolar Pedro Velho para o Grupo Escolar Felipe Camarão, em Ceará-Mirim (livro de Registro de títulos e portarias de licenças, 1923). Nessa instituição primária, criada pelo Decreto n 266 de março de 1912, Helena Botelho assumiu a Cadeira Infantil Mista IInscrição dos Grupos Escolares e Escolas Isoladas, 1924). 
Conforme entrevista com o senhor Odúlio Botelho, a professora Helena desenvolveu, nos municípios do Estado onde lecionou, uma "[...] intensa atividade cultural, procurando envolver a sociedade nas coisas da educação." Nas suas lembranças, "[...] além de poetisa, era uma excelente pintora. Desenvolvia uma boa oratória nos momentos solenes." (MEDEIROS, 2013).

Já aposentada do magistério, acompanhou o seu marido José Cesar de Farias Filho para o Estado da Paraíba, onde passou a residir no município de Princesa Isabel. "Continuou lecionando as crianças e adultos naquela região, era a vocação permanente sobre a arte de ensinar." (MEDEIROS, 2013). Por volta dos anos de 1970, residiu com sua família no bairro do Alecrim, à Rua Fônseca e Silva, n. 1 105. Depois morou na Rua Amaro Mesquita, Lagoa Nova, até os últimos dias de sua vida.

Destinou sua herança à filha de criação e sobrinha Lealzi Brandão.

[...] não tendo herdeiros necessários, quer ascendentes e quer descendentes, e podendo, por isso, livremente dispor da meação dos seus bens que então existirem por ocasião de sua morte, quer a ora determina que a referida meação de seus bens que então existirem por ocasião de sua morte, caibam e venham pertencer, exclusivamente, à sua sobrinha e filha de criação de nome Lealzi Brandão, brasileira, solteira, maior, de prendas domésticas, filha de Alexandre Brandão e de dona Alzira Botelho Brandão. (BOTELHO, 1971 , p. 21.

Helena Botelho faleceu em 24 de dezembro de 1986, aos 90 anos de idade. Morreu por falência múltipla dos órgãos pela senilidade. Seu sepultamento realizou-se no Cemitério do Alecrim.

Finalmente, ela denomina uma escola pública na zona rural do município de Taipú/RN, a Escola Isolada Helena Botelho, localizada no sítio Arisco dos Barbosa e faz parte das nossas pesquisas sobre a presença de professoras que configuraram a história da Leitura e da Escrita no Rio Grande do Norte.

\section{Grupo Escolar Joaquim Nabuco}

Município de Taipú localiza-se na microrregião do Litoral Norte do Estado do Rio Grande do Norte, distante 50 km da capital Natal. $\bigcirc$ nome 
Taipú tem sua origem em um aldeamento existente na localidade, denominado Itaipi. (CASCUDO, 1968).

Neste município foi criado o Grupo Escolar Joaquim Nabuco, em 1919. Essa instituição de ensino primário foi inaugurada oficialmente no dia 18 de fevereiro do mesmo ano. $O$ Jornal A República destacou que essa inauguração "[...] representa mais um dos grandes melhoramentos na instrução pública devido à administração fecunda e bem orientada do desembargador Ferreira Chaves." (GRUPO ESCOLAR, 1919, p. 2).

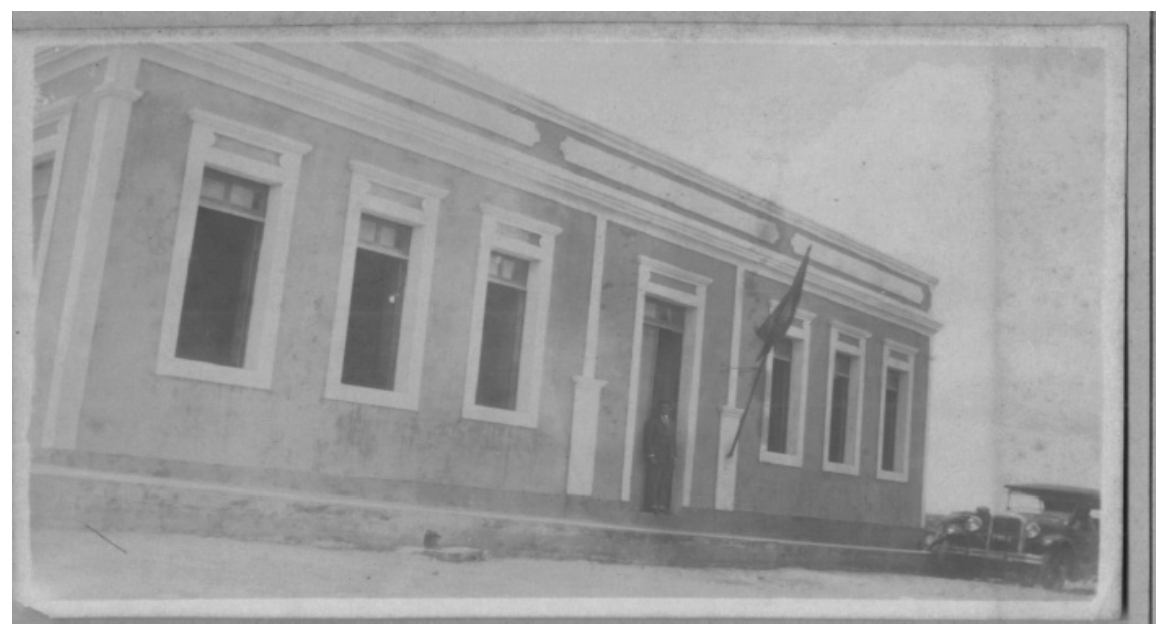

Imagem 2 | Fachada do Grupo Escolar Joaquim Nabuco | década de 1920 Fonte | Arquivo pessoal de Anderson Tavares | 2012

Grupo Escolar Joaquim Nabuco incorporou as escolas que existiam em Taipú, seguindo orientação da Diretoria-Geral da Instrução Pública. "Quando se tratar da criação de um grupo escolar, em localidade onde funcionem escolas isoladas, o grupo será organizado com a reunião dessas escolas [...]." (LEI No 405, DE 29 DE NOVEMBRO DE 1916, p. 47). Desse modo, funcionavam duas Escolas Isoladas no Grupo Escolar Joaquim Nabuco, sendo uma a Escola Isolada Feminina, regida pela professora Josefa Botelho, com 45 alunos matriculados e a outra a Escola Isolada Masculina, regida pela professora Helena Botelho, com a matrícula 40 alunos. Antes dessa organização, as Escolas Isoladas funcionavam nas residências dos próprios professores. Tal funcionamento acarretava problemas tanto de ordem administrativa quanto de 
ordem pedagógica, como a precariedade da estrutura física e de higiene e a falta de professores qualificados. As Escolas Isoladas passaram somente a pertencer ao patrimônio público a partir do momento em que o modelo de organização escolar das Cadeiras Isoladas foi sendo substancialmente modificado e substituído pelo modelo dos Grupos Escolares. (PINHEIRO, 2002).

$\bigcirc$ inspetor de ensino Amphiloquio Câmara em suas visitas escolares registrou a regularidade com que funcionava a Escola Isolada Masculina, " [...] além da boa ordem e disposição dos móveis, do asseio e bom comportamento dos alunos", e que a professora Helena Botelho cumpria os horários, programas e métodos de ensino oficialmente recomendados. IVISITAS ESCOLARES, 1919, p. 21.

As inspeções escolares tinham o objetivo de supervisionar o ensino, acompanhar a construção e o funcionamento dos estabelecimentos educacionais e orientar diretores e professores na organização técnica de suas classes e na adoção de métodos e processos de ensino recomendados pelo DiretorGeral da Instrução Pública. "A metodologia, a frequência, a caixa escolar, as festas e passeios escolares, assim como o aprendizado dos alunos, eram verificados periodicamente pelos inspetores escolares." (HOLLANDA, 2001, p. 74).

De acordo com Faria Filho (2000) ao registrarem os acontecimentos do cotidiano escolar, os inspetores de ensino, assim como os diretores e os professores estavam dando visibilidade aos grupos, permitindo tanto a observação quanto o controle e a possível intervenção nas atividades desenvolvidas em seu interior. Os relatórios produzidos concediam à Diretoria-Geral da Instrução Pública uma maneira de fiscalizar as atividades dos profissionais que atuavam nos estabelecimentos de ensino, de forma a manter sempre vivo os interesses do Estado.

A Lei Orgânica do Ensino criou em cada Grupo Escolar e Escola Isolada o Diário de Classe, no qual o professor deveria registrar o resumo dos trabalhos, com a indicação de lições, exercícios e deveres. (LEI N 405, DE 29 DE NOVEMBRO DE 1916).

Seguindo as orientações advindas da Diretoria-Geral da Instrução Pública, as professoras registravam as suas atividades nos Diários de Classe. A respeito das anotações de Helena Botelho, Amphiloquio Câmara declara: "[...] está regularmente feita, com clareza e asseio, tendo a professora o 
cuidado de antemão consignar no Diário de Classe, as lições a dar." Relata ainda que "[...] a professora proprietária da cadeira gosa da estima e da confiança sociais, pelo que a felicito, concitando-a a não esmorecer em meio da jornada." (VISITAS ESCOLARES, 1919, p. 2).

Percebemos que o Diário de Classe era um instrumento na inspeção escolar e na prática diária dos professores. A partir dele, obtivemos dados sobre as atividades docentes e o cotidiano da sala de aula.

No entanto, há lacunas. As brechas que se percebem nessa fonte documental, especialmente nos fragmentos, exigem uma reflexão sobre a necessidade de considerá-la não apenas como um elemento de importância na busca pelas concretizações do ensino, mas também como o atendimento às demandas burocráticas, nem sempre coerentes com as concepções construídas pelos professores, que procuram atender ao que thes é, muitas vezes, imposto. (AMÂNCIO; CARDOSO, 2011 ).

No Diário de Classe da professora estão dispostas as matérias que compunham o programa de ensino e o respectivo conteúdo a ser trabalho. Em consonância com a legislação vigente, as matérias eram: leitura; escrita e caligrafia; língua materna; cálculo aritmético; geometria, noções de geografia e história, especialmente, do Rio Grande do Norte; instrução moral e cívica; lições de coisas; desenho; hinos; trabalhos manuais; exercícios físicos. (LEl N ${ }^{\circ}$ 405, DE 29 DE NOVEMBRO DE 1916). Registrava as lições destinadas aos alunos e fazia referência à Cartilha de Ensino Rápido da Leitura, de Mariano de Oliveira.

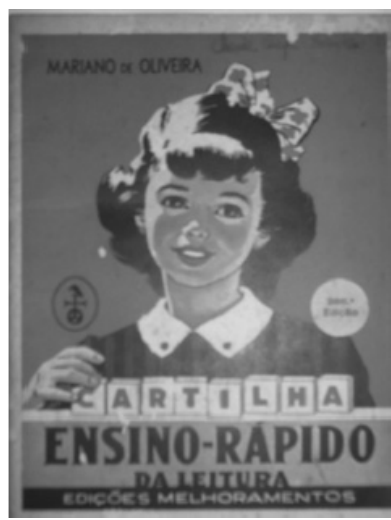

Imagem 3 | Cartilha de Ensino Rápido da Leitura Fonte | Oliveira | 1944 
Essa cartilha teve sua primeira edição em 1917, foi adotada oficialmente em pelo menos três estados brasileiros e considerada com uma das que teve maior circulação na escola primária brasileira, com $2232^{\circ}$ edições e mais de 6 milhões de exemplares, até 1997. (SOBRAL, 2007). Há registros, ainda, da utilização da Nova Cartilha Analítico-Sintética e do Livro de Leitura Páginas Infantis, ambas de Mariano de Oliveira. Pelo número de edições e títulos evidenciamos a grande aceitação que as publicações desse autor tiveram nos Grupos Escolares.

Para fins deste trabalho, analisamos a edição $266^{\circ}$ da Cartilha de Ensino Rápido da Leitura publicada em 1944. O motivo dessa escolha foi a ausência da primeira edição (1917) e por identificarmos semelhanças entre as atividades registradas pela professora Helena Botelho, em seu Diário de Classe, com as atividades dessa edição.

$\bigcirc$ método de ensino difundido na época em estudo era o Intuitivo. Desde a década de 1870, as criticas à instrução popular indicavam a necessidade de uma escola primária que em tudo se diferenciasse da escola de primeiras letras existentes. A escola popular, instrumento de reforma social, deveria ser totalmente renovada de acordo com os padrões educacionais considerados os mais modernos na época. $O$ método intuitivo foi o símbolo dessa renovação e modernização do ensino. (SOUZA, 1998).

Tal método consistia "[...] na valorização da intuição como fundamento de todo o conhecimento, isto é, a compreensão de que a aquisição dos conhecimentos decorria dos sentidos e da observação." (SOUZA, 1998, p. 159). Nesse sentido, o ensino deveria partir do particular para o geral, do conhecido para o desconhecido, do concreto para o abstrato. A prática do ensino concreto seria realizada pelas Lições de Coisas, considerada "[...] a chave para desencadear a pretendida renovação." (VALDEMARIN, 2004, p. 104).

\section{Leitura e Escrita}

A Leitura tanto quanto a Escrita faz parte do processo de construção, instauração dos sentidos. "A leitura não é somente uma operação abstrata de intelecção; ela é engajamento do corpo, inscrição num espaço, relação consigo e com os outros." (CHARTIER, 1994, p. 16). As práticas de Leitura 
e Escrita nos Grupos Escolares tinham por objetivo a formação da sociedade letrada norte-rio-grandense.

Os registros da professora Helena Botelho mostram que todos os dias os alunos tinham atividades acerca da Leitura e da Escrita, que também estavam presentes nas demais matérias. A exemplo, das aulas de cálculo e aritmética, nas quais os alunos faziam exercícios de "Copiar os algarismos de 1 até dez". (BOTELHO, 1919).

As crianças aprendiam a Leitura silenciosa que permitia a liberdade de imaginação sem a interferência de outrem. Por outro lado, a Leitura em voz alta possibilitava uma melhor compreensão do texto, através das entonações e pausas necessárias à fluência da Leitura. (MORAIS; SILVA, 2009). Helena Botelho trabalhava a Leitura com os alunos através da "Elocução sobre a leitura do dia" e a recitação de poesias infantis, contos e fábulas, como por exemplo, "A raposa e as uvas". (BOTELHO, 1919).

As lições da Cartilha de Ensino Rápido da Leitura demonstravam que exortações às virtudes e à valorização da natureza, do trabalho e da pátria eram frequentes.

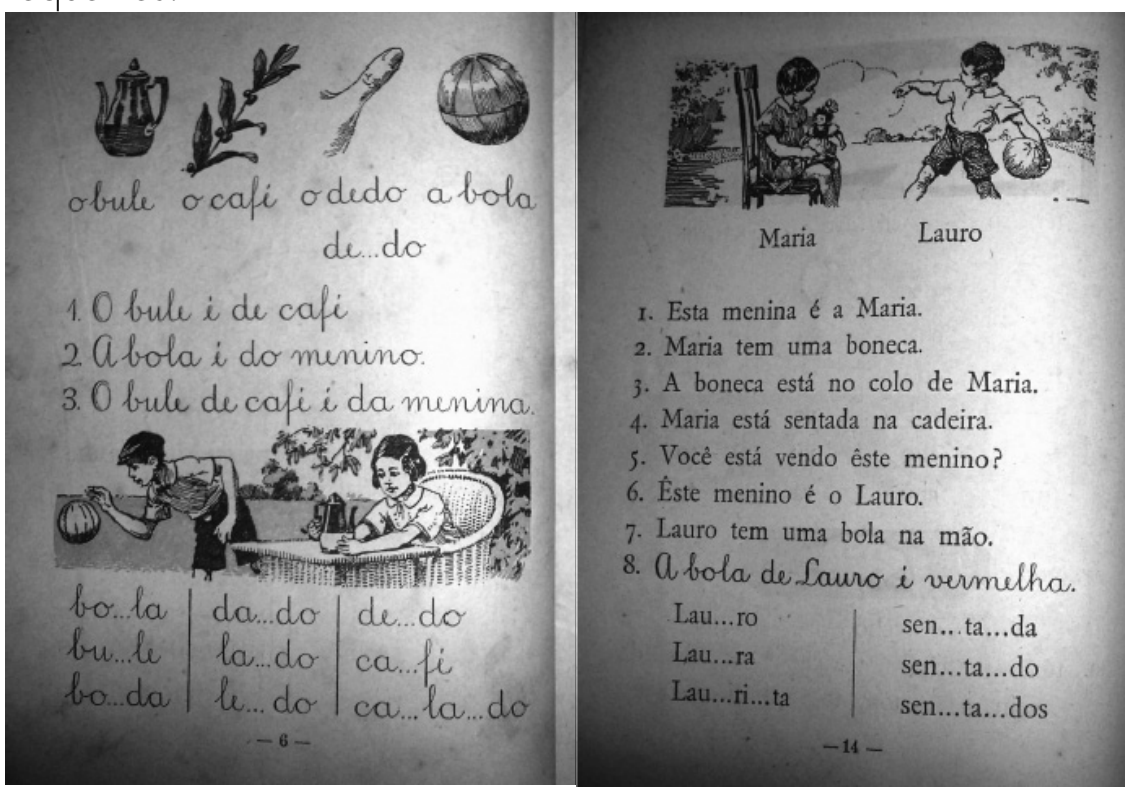

Imagem 4 | Páginas da Cartilha de Ensino Rápido da Leitura Fonte | Oliveira | 1944, p. 6;14 
As orações: "A bola é do menino", "Lauro tem uma bola na mão", "O bule de café é da menina" e "Maria tem uma boneca", expressam os valores a serem incutidos nos meninos e nas meninas que frequentavam o Grupo Escolar. Morais e Silva (2009) destacam que, para os meninos realizavam performances que condiziam com sua função de cidadão. Para as meninas o ensino valorizava atributos como leitura, considerado de bom tom para seu papel social de mãe, esposa, professora. A lição evidencia o papel socialmente construído para meninos e meninas.

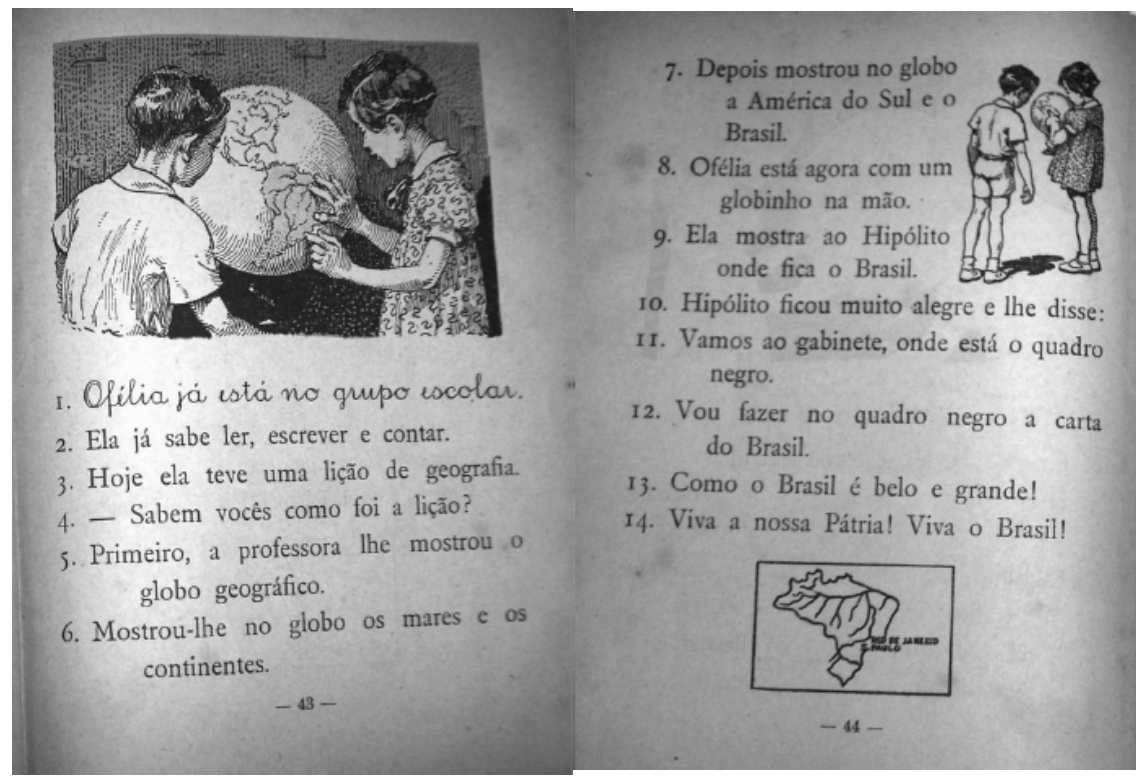

Imagem 5 | Páginas da Cartilha de Ensino Rápido da Leitura Fonte | Oliveira | 1944, p. 43-44

As ideias lançadas nos livros escolares tinham a intenção de mostrar às crianças a geografia do país e a ideologia dominante das divisões sociais de gênero, de trabalho e da escola. Frases como "Ofélia já está no grupo escolar" e "Ela já sabe ler e escrever", expressam as características da educação primária no início do século XX, bem como a altivez de pertencer à uma instituição escolar.

Não podemos perder de vista que a Cartilha de Ensino Rápido da Leitura surgiu em um contexto no qual havia o projeto de construção de uma sociedade letrada, já iniciado na segunda metade do século XIX. Desta feita, 
"[... ] valorizava-se a leitura como símbolo de instrução e como forma de socialização. A prática de leitura, portanto, entendida como uma chave de acesso ao saber erudito, ao brilho que a cultura letrada propicia." (MORAIS, 2002, p. 35). Nessa sociedade, o engrandecimento da pátria e a exaltação aos que já sabem ler são demonstrados a partir mesmo dos livros escolares. Nesse contexto, a escola adquire um papel singular.

Um papel singular demonstrado também na aprendizagem da Escrita, compreendida como "[...] a arte de gravar os nossos pensamentos e sentimentos, por meio de caracteres, chamados letras. A escrita é uma arte e não um dom natural [...] ela deve ser ensinada." (LIMA, 1911 b p. 1).

A organização da escrita no universo escolar modificou a organização do espaço, do tempo e das relações sociais: do espaço, lembrando que para escrever é necessário um lugar próprio; do tempo, percebendo que a escrita instaura a possibilidade da leitura posterior, o que confere maior durabilidade à palavra e maior relevância ao registro; e das relações sociais, compreendendo que a escrita cria uma nova dinâmica através do recurso às cartas, bilhetes ou mesmo anotações. (CHARTIER; HÉBRARD, 1998).

Conforme Lima (191 1 b p. 1) "[...] a boa escrita é regular, completa, inteligível." Assim, escrever tornou-se essencial para a construção da sociedade pretendida porque, "[...] com mais ou menos resistência, o público é moldado pelo escrito (verbal ou icônico), torna-se semelhante ao que recebe, enfim, deixa-se imprimir pelo texto e como o texto que the é imposto." ICERTEAU, 2012 , p. 238).

Os discursos pedagógicos, apoiados pelos preceitos higienistas da época, preocupavam-se em normatizar a escrita. Um dos princípios importantes durante a escrita em classe dizia respeito à disposição do corpo do aluno, do papel e da pena. A falta de cuidado com esses preceitos acarretaria problemas na visão, como a miopia, ou deformações na coluna da criança. (LIMA, 1911 b).

Para este particular, apresentavam-se três sistemas de escrita:

$\bigcirc 1^{\circ}$ começava pelas letras de duas pautas de tamanho e em ordem decrescente passava as de uma só, as de meia, até a letra comum ou cursivo; o $2^{\circ}$ sistema, reconhecendo que os dedos da criança não podem fazer as letras maiores, começava pelas menores, chegando afinal às maiores; o $3^{\circ}$ sistema, verificando a inconveniência de ambos, faz começar por um tamanho médio e na ordem decrescente, chega ao cursivo. (LIMA, 1911 b p. 1). 
A professora Helena Botelho revelava, no Diário de Classe, que nos ensinamentos sobre a Escrita, os exercícios estavam sempre aliados às atividades de Leitura. Registros como: "Copiar do quadro negro as palavras que estiverem no plural" ou "Cópia de um trecho da lição do dia, sublinhando as palavras que estiverem no singular", revelam isso. (BOTELHO, 1919).

Observamos na imagem abaixo que as atividades de Escrita eram realizadas em vários momentos ao longo do dia. Com destaque para o registro do uso da Cartilha de Ensino Rápido da Leitura e do Livro Páginas Infantis, ambas de Mariano de Oliveira.

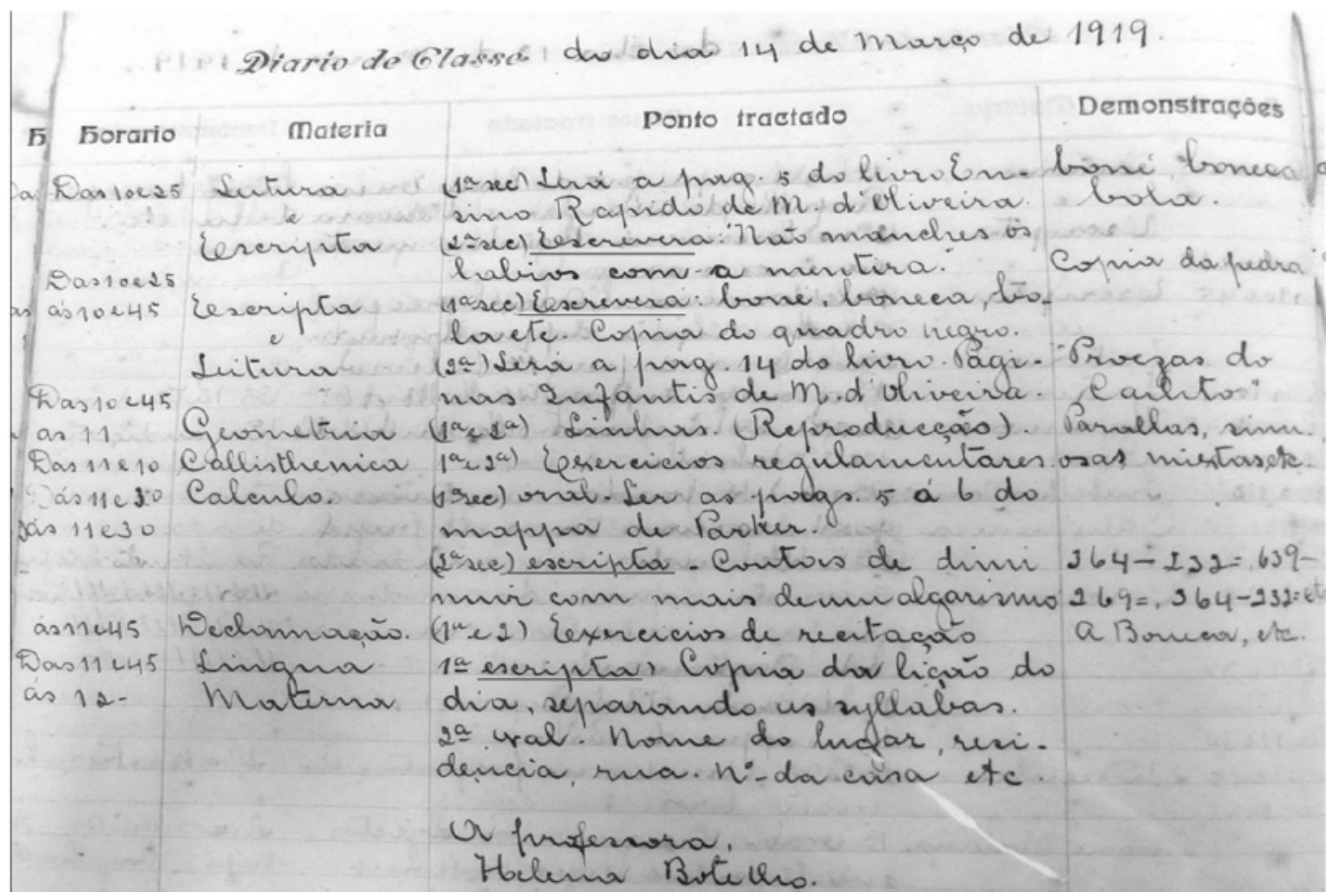

Imagem 6 | Registro das atividades de Escrita no Diário de Classe Fonte | Botelho | 1919

Na aprendizagem da Escrita a professora também preocupava-se em difundir os valores morais e patrióticos vigentes. É recorrente, nos seus registros, a utilização de frases que exaltavam a Pátria, o Trabalho e a Escola. Diariamente, os alunos escreviam frases como: "Tudo por minha Pátria!" ou "A bandeira da Pátria é digna de respeito". (BOTELHO, 1919). 
A temática Trabalho se destaca como prazerosa, digna, e gratificante. Revela-se claramente em exercícios registrados no Diário de Classe que sugeriam a escrita de frases como, por exemplo, "O trabalho engrandece $\circ$ homem", "O trabalho torna a vida feliz" e "O trabalho é a condição da felicidade". (BOTELHO, 1919).

A cópia diária de frases como "A escola não é lugar de conversa", "É necessária muita aplicação ao estudo", "É dever do aluno apresentar-se asseiado na escola" ou "Lá os alunos bons merecem a estima dos mestres" (BOTELHO, 1919) interiorizavam nas crianças o comportamento para o progresso a fim de que se tornassem cidadãos modernos e cultos.

\section{Lições de Coisas}

As Lições de Coisas, assim como a Leitura e a Escrita, permeavam as atividades docentes no período estudado. Consistia em aguçar o sentido da observação. Tinha como objetivo colocar a criança na presença das coisas, fazê-las ver, tocar, distinguir, nomear, medir, enfim, conhecê-las.

$170 \quad$ Em Periódicos da época é nítida a indicação nas escolas primárias das Lições de Coisas como o único caminho capaz de conduzirnos a uma educação sólida. Destaca que,

São as coisas que com seus nomes, nomes de suas propriedades, de suas ações, nos levam ao estudo da linguagem. É o estudo das formas dos objetos que produz a geometria, bem como o seu número fez nascer o cálculo. É do exame da localidade e de seus habitantes que resulta a geografia e a história. É o conhecimento dos animais, vegetais e minerais que produz a zoologia, a fitologia ou botânica e a mineralogia. (VASCONCELOS JÚNIOR, 1917, p. 8).

Para Nestor Lima, "[...] o estudo das coisas desenvolve as faculdades de observação e percepção (os sentidos), a memória, o juízo, o raciocínio, a abstração, a generalização, etc." (LIMA, 191 la, p. 1). Classifica-as em concretas, rudimentares e práticas. Concretas porque só devem ser dadas com o objeto a vista, o que provoca a observação do aluno, sobre o seu todo, suas partes, qualidades, etc.; Rudimentares, porque as inteligências infantis não comportam investigações sutis, discussão de teorias e leis; e Práticas porque 
devem ter um emprego na vida comum, como os alimentos, os objetos, noções de fisiologia, etc. (LIMA, 1911 a).

Neste sentido, esse autor sugere algumas etapas para o ensino das Lições de Coisas. $1^{\circ}$ Apresentação do objeto ou o seu desenho e sua denominação; observação pelos alunos das suas propriedades mais gerais, cor, forma, som, sabor e cheiro, conforme for possível; $2^{\circ}$ Designação de suas partes e elementos, bem como determinação de suas espécies ou variedades; $3^{\circ}$ Decomposição do objeto em seus elementos constitutivos e sua recomposição, se for possível; e $4^{\circ}$ Mostrar para que serve o objeto ou o funcionamento do órgão ou do ser. (LIMA, 191 la).

A Lei Orgânica do Ensino estabelece que nas instituições de ensino primário, as lições serão sobretudo práticas e concretas. "Os professores as encaminharão de modo que as faculdades do aluno sejam incitadas a um desenvolvimento gradual e harmônico, cumprindo ter em vista o desenvolvimento da faculdade de observação, empregando-se para isto processos intuitivos." (LEI No 405, DE 29 DE NOVEMBRO DE 1916, p. 44).

Observamos que a professora Helena Botelho, em seu Diário de Classe, descreve na matéria 'Coisas' exercícios de observação das "cores primárias e variedades", destaca suas distinções, tons e traz exemplos de cada cor primária. (BOTELHO, 1919, p. 6). Os seus registros apontam o trabalho com as temáticas animais, vegetais e alimentos, conforme Regimento Interno dos Grupos Escolares para o ensino das Lições de Coisas (Regimento Interno dos Grupos Escolares, 19251.

Ressaltava sempre a classificação, a exemplificação e as características dos assuntos abordados, como destacado no exemplo a seguir. 


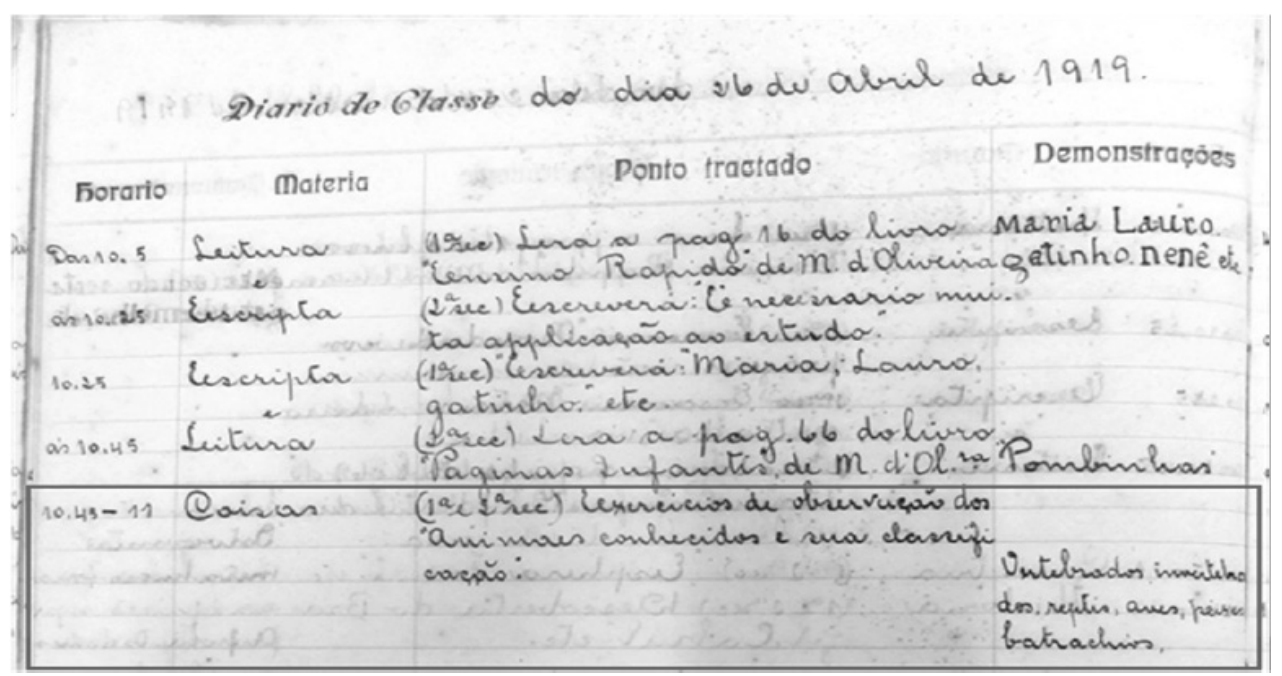

Imagem 7 | Registro das Lições de Coisas no Diário de Classe Fonte | Botelho | 1919

As Lições de Coisas estavam presentes nas demais matérias do programa de ensino. Nas aulas de Desenho, os alunos eram estimulados a desenhar livremente objetos relacionados com o cotidiano. Exemplos: "Uma colher de pedreiro", "Um banco escolar", "Um quadrado" e "Uma garrafa" (BOTELHO, 1919). A designação "Do natural" era utilizada para o desenho à mão livre, a partir da percepção das características que os alunos já interiorizaram do objeto. Explorar a memória dos alunos era uma das recomendações estabelecidas pelo Regimento Interno dos Grupos Escolares para os conteúdos da matéria de Desenho. (REGMENTO INTERNO DOS GRUPOS ESCOIARES, 1925).

Os preceitos das Lições de Coisas também se faziam presentes em atividades extraclasses. Os passeios escolares, recomendados pelo Regimento Interno dos Grupos Escolares, ocorriam, preferencialmente, nos campos de cultura, fábricas, estabelecimentos industriais e fazendas. (LEI N 405, DE 29 DE NOVEMBRO DE 1916). A República destacava o passeio escolar que a professora Helena Botelho realizou no sítio Umary, onde "Foram dadas lições sobre Botânica, a vista das plantas existentes no local, falando ainda a professora sobre a utilidade da árvore." (VISITAS ESCOLARES, 1920, p. 1).

Em outro passeio, ao sítio Rodeio, a "[...] professora da Escola Masculina aproveitando o plantio que se fazia, neste dia, de vários pés de 
Eucaliptos, explicou a necessidade e utilidade desta planta." IPASSEIOS ESCOLARES, 1920, p. 2). Nos passeios, após as lições, os alunos recrearam, executando exercícios de ginástica sueca, jogos infantis, corridas, poesias e cantando hinos escolares.

Outro espaço de aplicação das Lições de Coisas eram as festas realizadas na escola primária. $\bigcirc$ Regimento Interno dos Grupos Escolares instituiu três festas escolares obrigatórias: a Festa da Natureza, ou Festa da Árvore, que deveria ser realizada no dia 3 de maio, podendo ser uma reunião ou passeio geral, com plantio de árvores, atos de carinho aos animais domésticos; a Festa da Pátria, no dia 7 de setembro, com reunião cívica, recitativos, cânticos e entretenimentos alusivos a data, homenagem a Bandeira, recordação dos grandes nomes da Independência, havendo passeata geral quando possível; e a Festa da Bandeira, no dia 19 de novembro, com hasteamento da bandeira, às 12 horas na fachada do edifício, Hino de Bilac, saudações e palmas, passeio e homenagens especiais.

O Jornal A República relata a Festa da Árvore realizada no Grupo Escolar Joaquim Nabuco.

Às 16 horas, numa das áreas do recreio, perante numerosa assistência, teve inicio a festividade com o hino das árvores, entoado por todos os alunos. Em seguida, a professora Helena Botelho, em linguagem clara, falou às crianças sobre a utilidade da árvore, o carinho e o respeito com que deve ser tratada, terminando com um elogio ao trabalho. Em cada uma das áreas descobertas do recreio, foram plantadas duas mangueiras, por alunos das duas escolas. Num dos salões do Grupo, realizou-se uma parte recreativa, desempenhada pelos alunos, constante de diálogos e recitativos, cuidadosamente escolhidos e ensaiados pelas professoras. (A FESTA, 1920, p. 2).

Evidenciamos a presença constante das Lições de Coisas nas matérias e nas festividades realizadas na escola primária. Essa instituição utilizava o Método Intuitivo, as Lições de Coisas, para incutir valores e hábitos nas crianças. Compreendia-se que "Só os processos intuitivos podem levar o homem a raciocinar guiado pela razão, pelos princípios da ciência, pela compreensão das leis." (SOUZA, 1998, p. 164).

Desta maneira, a aprendizagem do ensino da Leitura e da Escrita ancorava-se nas Lições de Coisas, na intuição que conduz ao esclarecimento 
de novos conhecimentos. Observamos que o ensino-aprendizagem da Leitura e da Escrita centrava-se na valorização da intuição como fundamento de todo o conhecimento e as Lições de Coisas considerada a chave para desencadear a pretendida renovação do ensino.

\section{Palavras finais}

A professora Helena Botelho teve uma ação educativa voltada para a alfabetização de seus alunos, com ênfase nas cartilhas de ensino utilizadas pela política educacional da época. Indicava os modos de fazer e a conduta específica na escola primária do Rio Grande do Norte.

O Diário de Classe, assim como os passeios e as visitas escolares revelavam a narrativa do cotidiano escolar e o fazer de uma alfabetizadora em sala de aula. Os ensinamentos da Leitura, da Escrita e das Lições de Coisas são indícios de que as maneiras de educar as crianças envolviam controlar, semear e cultivar a natureza destas. São preceitos voltados para a formação do cidadão republicano.

174 Observamos que o fazer pedagógico dessa professora centrava-se na intuição e nas Lições de Coisas consideradas a chave para desencadear a pretendida renovação do ensino nas primeiras décadas do século XX. Enfim, a professora Helena Botelho sintonizava-se com as ideias correntes acerca da alfabetização no período analisado, demonstrando domínio no que transmitia aos alunos.

A metodologia que utilizamos permitiu vislumbrar, em parte, o cotidiano escolar, na concepção de Certeau (2012), e os modos diferenciados de apropriação da Leitura e da Escrita configuradas na construção desse contexto, sob as postulações de Chartier (1990) e Morais (2002).

Helena Botelho legitimou o magistério feminino no projeto de disseminação da instrução pública pelos recantos do Estado. Pioneira desse movimento - no sentido de que foi diplomada na primeira turma da Escola Normal de Natal (1910) -, enfrentou adversidades em favor do ensino público primário. Trata-se de uma professora que muito contribuiu para a formação da sociedade letrada Norte-rio-grandense. 


\section{Referências}

A FESTA das árvores. A República, Natal, p. 2, 19 maio 1920.

AMÂNCIO, Lázara Nanci de Barros; CARDOSO, Cancionila Janzkovski. História da Alfabetização em Mato Grosso: a contribuição dos "diários de classe" como fonte documental. In: MORTATTI, Maria do Rosário Longo (Org.). Alfabetização no Brasil: uma história de sua história. São Paulo: Cultura Acadêmica; Marilia: Oficina universitária, 2011.

BOTELHO, Helena. Diário de classe. Taipú (Rio Grande do Norte), mar./nov. 1919.

Escritura Pública de Testamento. Natal, 1971. (Documento datilografado de 31 de maio de 1971, sob a guarda do $5^{\circ}$ Ofício de notas, Alecrim - Natall.

CARVALHO, Marta Maria Chagas de. Reformas da instrução públicas. In: LOPES, Eliane Marta Teixeira; FARIA FILHO, Luciano Mendes de; VEIGA, Cynthia Greive (Org.). 500 anos de educação no Brasil. 3. ed. Belo Horizonte: Autêntica, 2003. (coleção historial, 6). p. 225-251.

CASCUDO, Luís da Câmara. Nomes da terra: geografia, história e toponímia do Rio Grande do Norte. Natal: Sebo Vermelho, 1968.

CERTEAU, Michel de. A invenção do cotidiano: 1. artes de fazer. 18. ed. Tradução Ephraim Ferreira Alves. Petrópolis, RJ: Vozes, 2012

CHARTIER, Roger. Historia cultural: entre práticas e representações. Tradução Maria Manuela Galhardo. Lisboa: Difel, 1990.

A ordem dos livros: leitores, autores e bibliotecas na Europa entre os séculos XIV e XVIII. Tradução Mary del Priore. Brasília: Editora Universidade de Brasília, 1994.

CHARTIER, Anne-Marie; HÉBRARD, Jean. A invenção do cotidiano: uma leitura, usos. Projeto História, São Paulo, n. 17, p. 29-44, nov. 1998.

COMBATER o analfabetismo é dever de honra de todo brasileiro. A República, Natal, p. 1, 24 set. 1917.

A República, Natal, p. 1, 11 jan. 1918.

A República, Natal, p. 1, 27 maio 1919.

DANTAS, Manoel. Contra o analfabetismo. A República, Natal, p. 1, 21 jul. 1917. 
FARIA FILHO, Luciano Mendes de. Dos pardieiros aos palácios: cultura escolar e urbana em Belo Horizonte na Primeira República. Passo Fundo: UPF, 2000.

GRUPO ESCOLAR Joaquim Nabuco. A República, Natal, p. 2, 19 fev. 1919.

HOLLANDA, Valkley Xavier Teixeira de. A expansão do ensino no RN (1910-1920): presença de professoras. 2001. 115 f. Dissertação (Mestrado em Educação) - Programa de Pós-Graduação em Educação, Universidade Federal do Rio Grande do Norte, Natal, 2001.

LIMA, Nestor dos Santos. A leitura, suas espécies, métodos e processos. A República, Natal, p. 1, 21 jul. 1911 . (Coluna Pedagogia).

- Lições de coisas, sua importância, princípio e método. A República, Natal, p. 1, 26 jul. 191 la. (Coluna Pedagogia).

A escrita, seus princípios e processos. A caligrafia. A República, Natal, p. 1, 28 jul. 191 1b. (Coluna Pedagogia).

MEDEIROS, Odúlio Botelho de. Entrevista. Natal, 23 jan. 2013.

MERCÊS, Juquinha das. Desanalfabetização. A República, Natal, p. 1, 1 jan. 1922.

176 MORAIS, Maria Arisnete Câmara de. Leituras de mulheres no século XIX. Belo Horizonte: Autêntica, 2002. 2006. 174p.

Chicuta Nolasco Fernandes, intelectual de mérito. Natal: Editorial A República,

História da leitura e da escrita no Rio Grande do Norte: presença de professoras (1910-1940). 201 1-2013. Projeto PVE2 $127-2011$ vinculado ao CNPq, Departamento de Educação, Universidade Federal do Rio Grande do Norte, Natal, 2011.

MORAIS, Maria Arisnete Câmara de; SILVA, Francinaide de Lima. Práticas de leitura e escrita nos grupos escolares do Rio Grande do Norte (1908-1920). Revista Educação em Questão, Natal, v. 36, n. 22, p. 114-138, set./dez. 2009.

Representações de professoras primárias no século XX: a primeira turma da Escola Normal de Natal (Rio Grande do Norte). In: FREITAS, Ana Maria Gonçalves Bueno de; MOTTA, Diomar das Graças (Org.). Mulheres na história da educação: desafios, conquistas e resistências. São Luís: EDUFMA: UFPB: Café \& Lápis, 2011.

OLIVEIRA, Mariano de. Cartilha de ensino rápido da leitura. 266. ed. Rio de Janeiro: Melhoramentos, 1944. 
PASSEIOS escolares. A República, Natal, p. 2, 22 jun. 1920. (Coluna Pelo Ensino).

PINHEIRO. Da era das cadeiras isoladas à era dos grupos escolares na Paraíba. Campinas: Autores Associados; São Paulo: Universidade São Francisco, 2002.

RIO GRANDE DO NORTE. Decreto n 178, de 29 de abril de 1908. Reestabelece a Diretoria Geral da Instrução Pública, cria a Escola Normal, Grupos Escolares e Escolas Mixłas e dá outras providências. Actos legislativos e decretos do governo. Natal: Typografia d'A República, 1908.

Lei n 249, de 22 de novembro de 1907. Autoriza o governo a reformar a instrução pública. Actos legislativos e decretos do governo. Natal: Typografia d'A República, 1908.

Decreto n 189, de 16 de fevereiro de 1909. Cria na cidade de Caicó um grupo escolar denominado Senador Guerra. Actos Legislativos e Decretos do Governo. Natal: Typografia d'A República, 1909.

Lei n 284, de 30 de novembro de 1909. Reforma a Instrução Pública do Estado. Actos legislativos e decretos do governo. Natal: Typografia d'A República, 1910.

Decreto $n^{\circ}$ 266, de 23 de março de 1912. Cria um grupo escolar na Cidade do Ceará-Mirim. Actos Legislativos e Decretos do Governo. Natal: Typografia d'A República, 1912.

Decreto $n^{\circ} 286$, de 10 de julho de 1913. Cria na cidade de Canguaretama, um grupo escolar denominado 'Pedro Velho'. Actos Legislativos e Decretos do Governo. Natal: Typografia d'A República, 1913.

Lei n 405, de 29 de novembro de 1916. Lei Orgânica do Ensino. Reorganiza o ensino primário, secundário e profissional, no Estado. Actos Legislativos e Decretos do Governo. Natal: Typografia d'A República, 1916.

Decreto n 86, de 8 de janeiro de 1919. Cria na Vila de Taipú um grupo escolar denominado 'Joaquim Nabuco'. Actos Legislativos e Decretos do Governo. Natal: Typografia d'A República, 1919.

Diretoria Geral de Instrução Pública do. Livro de Registro de títulos e portarias de licenças. Natal. 1923.

Diretoria Geral de Instrução Pública do. Inscrição dos grupos escolares e escolas isoladas. Natal, 1 fev. 1924. 
Departamento de Educação. Regimento Interno dos Grupos Escolares. Natal: Typografia d'A República, 1925.

SOBRAL, Patrícia de Oliveira. Um estudo sobre Nova Cartilha Analytico-Sinthética (1916), de Mariano de Oliveira. Revista de Iniciação Científica da Fundação Carlos Chagas, Marília/SP, v. 7, n. 3, p. 343-356, set./dez. 2007.

SOUZA, Rosa Fátima de. Templos de civilização: a implantação da escola primária graduada no Estado de São Paulo (1890-1910). São Paulo: Fundação Editora da UNESP, 1998.

VALDEMARIN, Vera Teresa. Estudando as lições de coisas: análise dos fundamentos filosóficos do método de ensino intuitivo. Campinas, SP: Autores Associados, 2004.

VASCONCELLOS JUNIOR, E. Benigno de. Lições de coisas. Revista de Ensino, Natal, v. I, n. 1, p. 6-8, fev. 1917.

VISITAS escolares Grupo Escolar 'Joaquim Nabuco'. A República, Natal, p. 2, 17 jun. 1919. (Coluna Pelo Ensino).

VISITAS escolares. A República, Natal, p. 1, 20 maio 1920. (Coluna Pelo Ensino).

178 5-6, fev. 1917.

WANDERLEY, Oscar. A leitura na escola primária. Revista de Ensino, Natal, v. I, n. 1, p.

Profa. Dra. Maria Arisnete Câmara de Morais Universidade Federal do Rio Grande do Norte | Natal Centro de Educação

Departamento de Fundamentos e Políticas da Educação Líder do Grupo de Pesquisa História da Educação, Literatura e Gênero Bolsista de Produtividade em Pesquisa do CNPq Nível 2 E-mail | maria.arisnete@pq.cnpq.br

Mestranda Karoline Louise Silva da Costa Universidade Federal do Rio Grande do Norte | Natal

Programa de Pós-Graduação em Educação Grupo de Pesquisa História da Educação, Literatura e Gênero E-mail | skarolinelouise@yahoo.com.br 
Graduanda Janaína Silva de Morais Universidade Federal do Rio Grande do Norte | Natal Curso de Pedagogia Bolsista de Iniciação Científica | CNPa Grupo de Pesquisa História da Educação, Literatura e Gênero E-mail | janinasmorais@gmail.com

Recebido 27 maio 2013 Aceito 11 jun. 2013 